\title{
Norepinephrine-Deficient Mice Have Increased Susceptibility to Seizure-Inducing Stimuli
}

\author{
Patricia Szot, ${ }^{1,6}$ David Weinshenker, ${ }^{2,5}$ Sylvia S. White, ${ }^{1}$ Carol A. Robbins, ${ }^{3}$ Nicole C. Rust, ${ }^{2,5}$ \\ Philip A. Schwartzkroin, ${ }^{3,4}$ and Richard D. Palmiter ${ }^{2,5}$ \\ Departments of ${ }^{1}$ Psychiatry and Behavioral Science, ${ }^{2}$ Biochemistry, ${ }^{3}$ Neurological Surgery, and ${ }^{4}$ Physiology/Biophysics \\ and ${ }^{5}$ Howard Hughes Medical Institute, University of Washington, Seattle, Washington 98195, and ${ }^{6}$ GRECC, Puget \\ Sound Health Care System, Seattle, Washington 98108
}

\begin{abstract}
Several lines of evidence suggest that norepinephrine (NE) can modulate seizure activity. However, the experimental methods used in the past cannot exclude the possible role of other neurotransmitters coreleased with NE from noradrenergic terminals. We have assessed the seizure susceptibility of genetically engineered mice that lack NE. Seizure susceptibility was determined in the dopamine $\beta$-hydroxylase null mutant ( $D b h$ $-/-)$ mouse using four different convulsant stimuli: 2,2,2trifluroethyl ether (flurothyl), pentylenetetrazol (PTZ), kainic acid, and high-decibel sound. Dbh -/- mice demonstrated enhanced susceptibility (i.e., lower threshold) compared with littermate heterozygous ( $D b h+/-)$ controls to flurothyl, PTZ, kainic acid, and audiogenic seizures and enhanced sensitivity (i.e., seizure severity and mortality) to flurothyl, PTZ, and kainic
\end{abstract}

Chen et al. (1954) first suggested that the noradrenergic system modifies seizure activity. Since then, four major observations have supported an anticonvulsant role for norepinephrine (NE): (1) selective lesioning of noradrenergic neurons (with 6-hydroxydopamine or DSP-4) increases seizure susceptibility to a variety of convulsant stimuli (Arnold et al., 1973; Jerlicz et al., 1978; Mason and Corcoran, 1979; Snead, 1987; Trottier et al., 1988; Sullivan and Osorio, 1991; Mishra et al., 1994); (2) direct stimulation of the locus coeruleus (LC, the major concentration of noradrenergic cell bodies in the CNS) and the subsequent release of NE reduce CNS sensitivity to convulsant stimuli (Libet et al., 1977; Turski et al., 1989); (3) genetically epilepsy-prone rats (GEPRs), a widely used animal model of epilepsy, have deficient presynaptic NE content, NE turnover, tyrosine hydroxylase levels, dopamine $\beta$-hydroxylase (DBH) levels, and NE uptake (Jobe et al., 1984; Dailey and Jobe, 1986; Browning et al., 1989; Lauterborn and Ribak, 1989; Dailey et al., 1991); and (4) adrenergic agonists acting at the $\alpha-2$ adrenoreceptor $(\alpha 2$-AR) have anticonvulsant action (Papanicolaou et al., 1982; Baran et al., 1985; Loscher and Czuczwar, 1987; Fletcher and Forster, 1988; Jackson et al., 1991).

Received July 7, 1999; revised Sept. 28, 1999; accepted Sept. 30, 1999.

This work was supported by the National Alliance for Research on Schizophrenia and Depression (P.S.), the Department of Veterans Affairs (P.S.), National Institutes of Health Grant NS-18895 (P.A.S.), and the Howard Hughes Medical Institute (D.W. and N.C.R). We thank Sumitomo Pharmaceuticals for their generous donation of DOPS.

P.S. and D.W. contributed equally to this work.

Correspondence should be addressed to Dr. Patricia Szot, Geriatric Research, Education, and Clinical Center (182B), Veterans Affairs Medical Center, 1660 South Columbian Way, Seattle, WA 98108. E-mail: szot@u.washington.edu.

Copyright $\odot 1999$ Society for Neuroscience $\quad 0270-6474 / 99 / 1910985-08 \$ 05.00 / 0$ acid. c-Fos mRNA expression in the cortex, hippocampus (CA1 and CA3), and amygdala was increased in Dbh -/- mice in association with flurothyl-induced seizures. Enhanced seizure susceptibility to flurothyl and increased seizure-induced c-fos mRNA expression were reversed by pretreatment with L-threo3,4-dihydroxyphenylserine, which partially restores the NE content in $D b h-/-$ mice. These genetically engineered mice confirm unambiguously the potent effects of the noradrenergic system in modulating epileptogenicity and illustrate the unique opportunity offered by $D b h-/-$ mice for elucidating the pathways through which NE can regulate seizure activity.

Key words: dopamine $\beta$-hydroxylase; c-fos mRNA; norepinephrine; flurothyl; epilepsy; seizure; kainic acid

Although there is significant evidence that the NE system is anticonvulsant, there are several considerations that temper one's confidence in the hypothesis that NE, itself, reduces seizure sensitivity. For example, although the lesioning studies (i.e., chemical destruction of noradrenergic terminals) reduce the amount of NE release, this manipulation also reduces the release of other transmitters coreleased with NE. The neuropeptides galanin and neuropeptide Y (NPY) and the neurotransmitter adenosine (i.e., ATP) are released at noradrenergic terminals and have been shown to exert anticonvulsant effects against several convulsant stimuli (Murray et al., 1985; Mazarati et al., 1992, 1998; Dichter, 1994; Erickson et al., 1996; Baraban et al., 1997). A similar argument can be made for the anticonvulsant effect of direct LC stimulation, which results in the release not only of NE but also of these cotransmitters. The enhanced seizure sensitivity of the GEPRs may not be caused solely by their abnormal noradrenergic system, because these animals also have abnormalities in their central serotonergic, GABAergic, and excitatory amino acid systems (Faingold et al., 1986; Dailey et al., 1992; Meyerhoff et al., 1992); moreover, other animal models of epilepsy have a higher than normal central NE content (Noebels, 1986; Hara et al., 1993). Finally, the $\alpha 2$-AR pharmacological studies are difficult to interpret because the effect of clonidine ( $\alpha 2$-AR agonist) on seizure-induced activity can be biphasic, nonexistent, or even proconvulsant (King and Burnham, 1982; Tacke and Kolonen, 1984; Lapin and Ryzor, 1990). Such multiple responses to $\alpha 2$-AR agonists may be caused by the localization of the affected $\alpha 2$-AR. Activation of presynaptic $\alpha 2$-AR autoreceptors would reduce transmitter released at NE terminals (L'Heureux et al., 1986), whereas activation of postsynaptic $\alpha 2$-ARs would mimic the effect 
of released NE. Because it has not been determined whether the anticonvulsant effect of $\alpha 2-\mathrm{AR}$ agonists is mediated via pre- or postsynaptic receptors, it remains unclear whether increased NE release is anti- or proconvulsant.

Taken together, these studies suggest that changes in noradrenergic functions (terminal $\mathrm{NE}$ content or release) can modulate seizure activity, but they do not resolve the issue of whether NE is, itself, anticonvulsant. It is this issue that we have addressed with the DBH null mutant $(D b h-/-)$ mouse. These animals selectively lack NE and epinephrine (dopamine content tends to be elevated) because $\mathrm{DBH}$ is required for the conversion of dopamine to NE (Thomas et al., 1998).

\section{MATERIALS AND METHODS}

Animals. Mice were derived from a hybrid line (129/Sv/Ev and C57BL/ $6 \mathrm{~J})$. $D b h-/-$ and heterozygote $(D b h+/-)$ mice were bred as described previously (Thomas et al., 1995). Mice were maintained on a $12 \mathrm{hr}$ light/dark cycle in a specific pathogen-free facility at the University of Washington (Seattle, WA). Food and water were available ad libitum, and animals were maintained according to the guidelines outlined in the NIH Guide for Care and Use of Laboratory Animals. All animal procedures were approved by the University of Washington Animal Care Committee. Genotype was deduced from phenotype (Dbh $-/-$ mice exhibit delayed growth during adolescence and ptosis), and a subset of mice was confirmed by PCR (Thomas et al., 1995). $D b h+/-$ mice are indistinguishable from wild-type $(+/+)$ mice as to $\mathrm{NE}$ and epinephrine levels (Thomas et al., 1998). Preliminary studies showed no significant difference in seizure susceptibility [2,2,2-trifluroethyl ether (flurothyl)induced seizures] between wild-type $(+/+)$ and heterozygote $D b h(+/-)$ mice; therefore, $D b h+/-$ mice were used as controls in all experiments. Adult (3-6 months) male and female littermates of each genotype were evenly distributed to experimental and control groups for each convulsant stimulus. A subset of animals will receive a single intraperitoneal injection of L-threo-3,4-dihydroxphenylserine (DOPS; $1 \mathrm{mg} / \mathrm{gm}$ ). DOPS is converted to NE by aromatic L-amino acid decarboxylase, which is present in all biogenic amine neurons. Five hours after a single administration of DOPS, NE levels peak in peripheral and central regions; dopamine levels are not affected by DOPS (Thomas et al., 1998).

Flurothyl susceptibility. Flurothyl seizure thresholds were determined for $D b h+/-$ and $D b h-/-$ mice, with and without previous administration of DOPS. Mice were placed in an air-tight Plexiglas chamber, and the volatile convulsant flurothyl (Aldrich, Milwaukee, WI) was infused (20 $\mu \mathrm{l} / \mathrm{min}$ ) onto filter paper from which it vaporized (Prichard et al., 1969). The latencies (seconds) to the first myoclonic jerk (focal seizure) and to generalized (clonic/tonic) seizure served as the measurements of seizure susceptibility. Each mouse was tested individually, removed immediately from the chamber after seizure onset, and received only one exposure to flurothyl. Some animals received DOPS (1 mg/gm, i.p.) $6 \mathrm{hr}$ before seizure-threshold testing. Latency (seconds) data from each group were expressed as the mean \pm SEM and were analyzed with Student's $t$ test comparisons; statistical significance was taken at $p<0.05$. For each group ( $D b h-/-$ and $D b h+/-$ mice, with and without DOPS), we also determined the percentage of animals proceeding to tonic extension followed by recovery versus the percentage progressing to death. Surviving animals were killed $1 \mathrm{hr}$ after the seizure to measure c-fos mRNA expression.

Pentylenetetrazol susceptibility. Pentylenetetrazol (PTZ) at two different doses (30 and $40 \mathrm{mg} / \mathrm{kg}$, i.p.) was administered to both $D b h+/-$ and $D b h-/-$ mice. After injection, the animals were placed into a clear container and closely monitored for $10 \mathrm{~min}$. The latencies (seconds) to the first myoclonic jerk (focal seizure), to forelimb clonus, and to generalized (clonic/tonic) seizures were measured and analyzed as described above.

Kainic acid susceptibility. Kainic acid (stock solution, $4 \mathrm{mg} / \mathrm{ml}$ ) was dissolved in neutral-buffered saline and administered to both $D b h+/-$ and $D b h-1-$ mice at an intraperitoneal dose of $20 \mathrm{mg} / \mathrm{kg}$. After injection, the animals were placed into a clear container and closely monitored for $40 \mathrm{~min}$. The latency (seconds) to the first generalized (clonic/tonic) seizure was measured and was analyzed as described above. For each group, we also determined the percentage of animals that progressed to death.

Audiogenic seizure susceptibility. Audiogenic seizure sensitivity in Dbh
+/- and $D b h-/-$ mice was determined by exposing animals to a $115 \mathrm{~dB}$ sound for $60 \mathrm{sec}$ with an SR Pilot (San Diego Instruments, San Diego, $\mathrm{CA})$. After the sound was started, the mouse was closely monitored for occurrence of a seizure. If no seizure occurred, the sound was terminated after $60 \mathrm{sec}$. If a seizure was observed during the $60 \mathrm{sec}$ period, the sound was immediately terminated, and the animal was removed. Mice were scored as exhibiting or not exhibiting a seizure.

c-Fos $m R N A$ expression after flurothyl-induced seizures. The mice that survived flurothyl-induced generalized seizures were killed by cervical dislocation $1 \mathrm{hr}$ after the seizure $[\mathrm{Dbh}+/-(n=8)$ and $D b h-/-(n=$ 6) without DOPS; $D b h+/-(n=8)$ and $D b h-/-(n=9)$ with DOPS]. To determine basal c-fos mRNA expression $D b h+/-(n=6)$ and $D b h$ $-/-(n=6)$ mice (same age as the flurothyl-tested mice) were also killed. Brains were collected from each animal and immediately frozen on dry ice. Twenty micrometer coronal sections containing neocortex and hippocampus were cut on a cryostat and mounted onto Fisher Superfrost slides (Fisher Scientific, Houston, TX). Slides were stored at $-70^{\circ} \mathrm{C}$ until assayed.

Tissue preparation and labeling of the c-fos oligonucleotide was performed as described previously (Szot et al., 1997). The c-fos oligonucleotide probe was a 51-base probe complementary to nucleotides 270-319 of the c-fos mRNA (Curran et al., 1987). The oligonucleotide probe was 3 '-end-labeled with $\left[{ }^{33} \mathrm{P}\right] \mathrm{dATP}$ (New England Nuclear, Boston, MA) using terminal deoxyribonucleotidyl transferase (Life Technologies, Gaithersburg, MD) and then purified on NEN-Sorb columns (New England Nuclear). The c-fos hybridization buffer for the flurothylinduced seizure assay contained $0.3 \times 10^{6} \mathrm{cpm} / 50 \mathrm{ml}$. The c-fos hybridization buffer for the basal assay contained $0.4 \times 10^{6} \mathrm{cpm} / 50 \mathrm{ml}$. Hyperfilm (Amersham, Arlington Heights, IL) was exposed to slides containing tissue hybridized with c-fos $\left[{ }^{33} \mathrm{P}\right]$ oligonucleotide for $1 \mathrm{~d}$ for the flurothyl-induced seizure assay and $5 \mathrm{~d}$ for the basal assay. To quantitate c-fos mRNA expression in the specific regions of the CNS, all sections were processed, hybridized, and washed in the same experimental session. Each sheet of Hyperfilm contained sections from all four groups ( $D b h+/-$ and $D b h-/-$ mice with and without DOPS). To determine basal c-fos mRNA expression, sections from $D b h+/-$ and $D b h-/-$ mice were processed, hybridized, and washed in a similar manner. Optical densities were measured from films using the MicroComputer Imaging Device (Imaging Research, Ontario, Canada). Separate optical density measurements were made of the left and right hemispheres over three successive sections, which were anatomically matched across animals according to the atlas of Franklin and Paxinos (1997). Background optical density was subtracted from each image. Each mean \pm SEM reported here is the averaged value of six optical density readings (after background subtraction) for each animal. Data were analyzed by Student's $t$ test; statistical significance was taken as $p<0.05$.

\section{RESULTS}

\section{Dbh -/- mice have increased susceptibility to epileptic stimuli}

\section{Flurothyl}

Dbh $-/-$ mice without DOPS had significantly reduced latencies to the first myoclonic jerk $(\mathrm{MJ})$ and clonic/tonic $(\mathrm{C} / \mathrm{T})$ seizure compared with $D b h+/-$ controls (Fig. $1 A, B$, without DOPS). The latency to the first $\mathrm{MJ}$ was affected to a greater degree $(46 \%$ reduction) than the latency to $\mathrm{C} / \mathrm{T}$ convulsion (29\% reduction). The percent of $D b h-/-$ and $D b h+/-$ mice progressing to tonic extension after a $\mathrm{C} / \mathrm{T}$ seizure was identical (45\%); however, $100 \%$ of the $\mathrm{Dbh}-/-$ mice died after C/T seizure, whereas only $60 \%$ of the $D b h+/-$ mice died after tonic extension (Table 1). The higher mortality rate of $D b h-/-$ mice was not a function of the duration of flurothyl exposure, because the average duration of exposure was shorter for the $D b h-/-$ than for the $D b h+/-$ animals.

$\mathrm{NE}$ levels are partially restored in the CNS of $D b h-/-$ mice by the administration of DOPS (Thomas et al., 1998). Administration of DOPS to $D b h-/-$ mice significantly lengthened the latency to the first $\mathrm{MJ}$ and $\mathrm{C} / \mathrm{T}$ convulsion (Fig. $1 A, B$ with DOPS); latencies to $\mathrm{MJ}$ and $\mathrm{C} / \mathrm{T}$ convulsions in $D b h-/-$ mice 
A Time to first myoclonic jerk

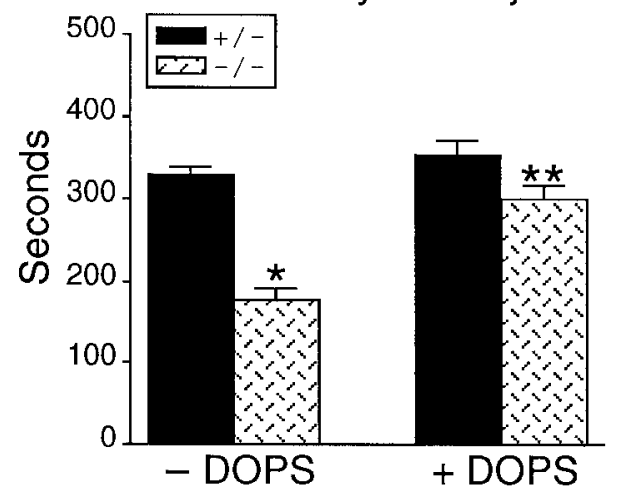

B Time to clonic/tonic seizure

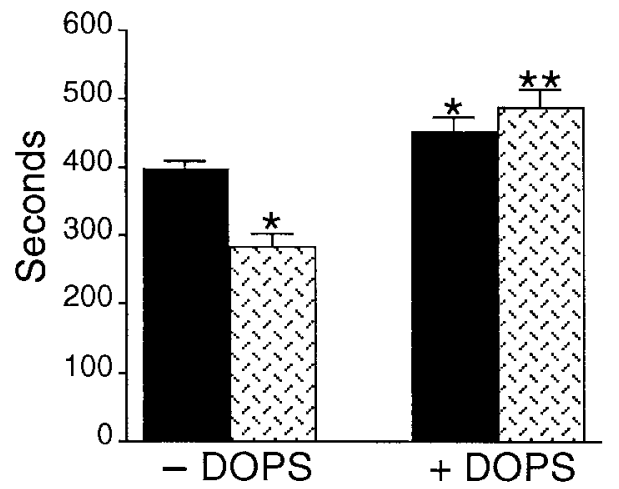

Figure 1. Responsiveness of $D b h+/-$ and $D b h-/-$ mice to flurothylinduced seizures. Latencies (seconds) to first MJ $(A)$ and clonic/tonic seizure $(B)$ recorded in $D b h+/-$ and $D b h-/-$ mice, with and without the administration of DOPS. $D b h-/-$ mice without DOPS had significantly shorter latencies to $\mathrm{MJ}(A)$ and $\mathrm{C} / \mathrm{T}$ seizures $(B)$ compared with $D b h+/-$ mice without DOPS (mean \pm SEM; single asterisks denote $p<$ 0.05). Administration of DOPS (1 mg/gm) $6 \mathrm{hr}$ before flurothyl significantly increased flurothyl latencies in the $D b h-/-$ mice compared with the $D b h-/-$ mice without DOPS for both MJ $(A)$ and $\mathrm{C} / \mathrm{T}$ seizures $(B)$ (mean \pm SEM; double asterisks denote $p<0.05$ ). Latencies to both MJ and $\mathrm{C} / \mathrm{T}$ convulsions in $\mathrm{Dbh}-/-$ mice with DOPS were not significantly different compared with those in $D b h+/-$ mice with DOPS.

with DOPS were not statistically different from latencies in $D b h$ $+/-$ mice with DOPS. Administration of DOPS to $D b h+/-$ mice did not significantly alter the latency to the first MJ but significantly increased the latency time to $\mathrm{C} / \mathrm{T}$ seizures (Fig. 1). Administration of DOPS to $D b h-/-$ and $D b h+/-$ mice did not affect the number of animals progressing to tonic extension but did reduce the number of animals dying after tonic extension in both groups (Table 1).

\section{Pentylenetetrazol}

Dbh $-/-$ and $D b h+/-$ mice were challenged with PTZ at 30 and $40 \mathrm{mg} / \mathrm{kg}$, and the latencies (seconds) to the first MJ, forelimb clonus (FC), and C/T were measured (Fig. 2). PTZ (40 mg/kg) induced generalized seizures in all $D b h-/-$ mice (eight of eight) but in only four of seven $D b h+/-$ mice. Latencies to MJ, FC, and $\mathrm{C} / \mathrm{T}$ seizures in $D b h-/-$ mice were significantly shorter than those in $D b h+/-$ mice (Fig. $2 A$ ). The percent of animals exhibiting tonic extension was greater in $D b h-/-$ mice (100\%) than in $D b h+/-$ mice $(29 \%)$; however, for both genotypes, all animals exhibiting tonic extension died (Fig. $2 A$ ).

PTZ $(30 \mathrm{mg} / \mathrm{kg})$ induced C/T seizures in 8 of $10 \mathrm{Dbh}-/-$ mice and in 2 of $9 \mathrm{Dbh}+/-$ mice. Of these animals exhibiting seizures, the $D b h-/-$ mice had significantly shorter latencies to the first MJ, FC, and C/T seizures than did Dbh $+/-$ mice (Fig. $2 B$ ). Again $100 \%$ of the $D b h-/-$ mice that exhibited seizure activity progressed to tonic extension and death; however, only $11 \%$ of the $D b h+/-$ mice that exhibited seizure activity had tonic extension, and of those, only $44 \%$ died.

\section{Kainic acid}

Kainic acid (KA; $20 \mathrm{mg} / \mathrm{kg}$ ) induced some seizure behavior (i.e., staring, head nodding, and forelimb clonus) in most animals in both groups; however KA induced generalized $\mathrm{C} / \mathrm{T}$ convulsions in $100 \%$ of the $\mathrm{Dbh}-/-$ mice (eight of eight) but in only $38 \%$ of the $D b h+/-$ mice (three of eight). Of the animals showing $\mathrm{C} / \mathrm{T}$ convulsions, $D b h-/-$ mice had a significantly shorter latency to generalized seizure $(1587 \pm 188 \mathrm{sec})$ than did $D b h+/-$ mice $(2243 \pm 120 \mathrm{sec})$. The $D b h-/-$ mice also exhibited enhanced sensitivity to KA compared with $D b h+/-$ mice; $50 \%$ of the $D b h$ $-/-$ mice died after the KA-induced seizure, whereas none of the $D b h+/-$ mice died.

\section{Audiogenic seizures}

The $D b h-/-$ mice were more sensitive to the acoustic stimuli than were $D b h+/-$ mice, in that $50 \%$ (5 of 10) of the $D b h-/-$ mice exhibited a generalized seizure during the sound stimulus, whereas only $11 \%$ (1 of 9) of the $D b h+/-$ exhibited a generalized convulsion. Seizures were initiated shortly after onset of the sound (latencies between 3 and $12 \mathrm{sec}$ ) and manifested initially as jumping behavior that progressed quickly to explosive runningbouncing activity and finally to tonic extension and death. Sensi-

\section{(A) PTZ (40 mg/kg)}
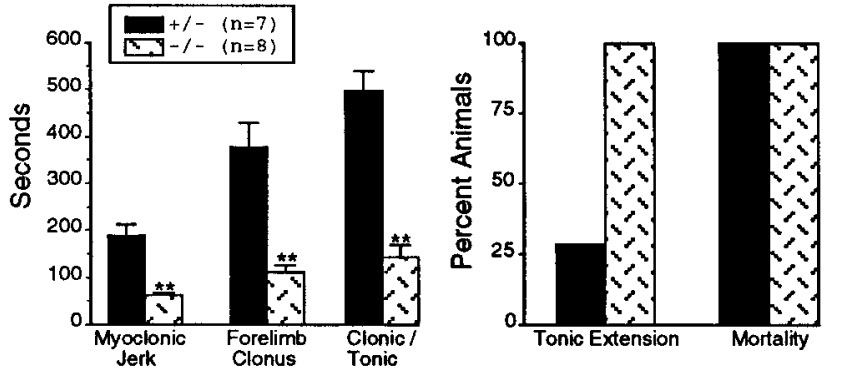

(B) PTZ (30 mg/kg)
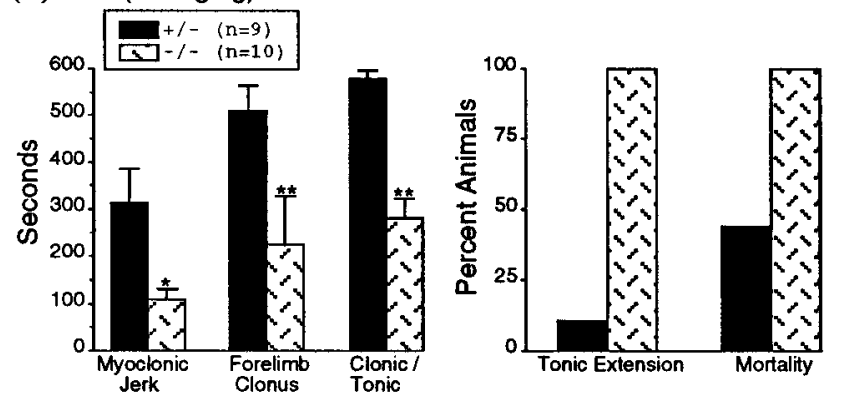

Figure 2. Responsiveness of $D b h+/-$ and $D b h-/-$ mice to PTZ injections at $40 \mathrm{mg} / \mathrm{kg}(A)$ and $30 \mathrm{mg} / \mathrm{kg}(B)$. Left, Graphs show seizure latencies (seconds) to the first myoclonic jerk, forelimb clonus, and clonic/ tonic seizure in $D b h-/-$ and $D b h+/-$ mice. At both PTZ concentrations $D b h-/-$ mice had significantly shorter latencies compared with those in Dbh $+/-$ mice (mean \pm SEM; single asterisk denotes $p<0.01$; double asterisks denote $p<0.001)$. Right, Graphs show the percentage of animals progressing to tonic extension and the percentage of animals that died after tonic extension (mortality). 
Table 1. Number of animals used for flurothyl-induced seizures with and without the administration of DOPS

\begin{tabular}{|c|c|c|c|c|}
\hline & \multicolumn{2}{|c|}{ Without DOPS } & \multicolumn{2}{|c|}{ With DOPS } \\
\hline & $+/-$ & $-1-$ & $+/-$ & $-1-$ \\
\hline Flurothyl-induced seizures & $n=11$ & $n=11$ & $n=9$ & $n=11$ \\
\hline$\%$ tonic extension & $45(5 / 11)$ & $45(5 / 11)$ & $44(4 / 9)$ & $54(6 / 11)$ \\
\hline$\%$ mortality & $60(3 / 5)$ & $100(5 / 5)$ & $25(1 / 4)$ & $33(2 / 6)$ \\
\hline
\end{tabular}

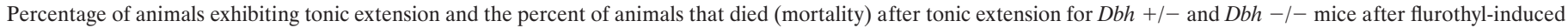
seizure.

tivity to sound-induced seizure was identical between the groups of animals; all animals (i.e., in both $D b h-/-$ and $D b h+/-$ groups) that exhibited a sound-induced generalized seizure died.

\section{Dbh -/- mice have increased c-fos mRNA associated with flurothyl-induced seizures}

The animals that survived flurothyl-induced seizures $[D b h+/-$ $(n=8)$ and $D b h-/-(n=6)$ without DOPS; Dbh $+/-(n=8)$ and $D b h-/-(n=9)$ with DOPS] were killed $1 \mathrm{hr}$ after C/T seizures to measure c-fos mRNA expression. Seizure-induced c-fos mRNA expression was quantitated in the neocortex, amygdala, and hippocampus [CA1, CA3, and dentate gyrus (DG)] [see Figs. 3 (for representative autoradiograms), 4 (for quantitative comparisons)].

In the neocortex, $D b h-/-$ mice had significantly greater seizure-induced c-fos mRNA expression than did the $D b h+/-$ mice, even though the two different genotypes had similar seizure-induced behavior (generalized seizures). Administration of DOPS to $D b h-/-$ mice reduced seizure-associated c-fos mRNA expression to a level comparable with that seen in the neocortex of $D b h+/-$ mice, without or with DOPS (Fig. 4). Administration of DOPS to Dbh $+/-$ mice did not alter seizureassociated c-fos mRNA expression in the neocortex.

Similar results were obtained in the hippocampal CA1 and CA3 regions and the amygdala. Flurothyl seizure-associated c-fos mRNA expression in $D b h-/-$ mice was significantly higher than that in $D b h+/-$ mice in CA1 and CA3 regions and the amygdala. Administration of DOPS to $D b h-/-$ mice significantly reduced the flurothyl seizure-associated c-fos mRNA expression (to the level observed in $D b h+/-$ mice with DOPS). Flurothyl seizure- associated c-fos mRNA expression in $D b h+/-$ mice was not significantly changed by DOPS pretreatment. The only region where c-fos mRNA expression was not significantly different between $D b h-/-$ and $D b h+/-$ mice was in the DG. Administration of DOPS to both genotypes also had no effect on flurothylinduced c-fos mRNA expression in the DG. Because the Dbh -/- mice had elevated seizure-associated c-fos mRNA expression in the neocortex, hippocampal CA1 and CA3, and amygdala, basal c-fos mRNA was measured in $D b h+/-$ and $D b h-/-$ mice. Basal c-fos mRNA expression in $D b h-/-$ mice was not significantly different from that in $\mathrm{Dbh}+/-$ mice (data not shown).

\section{DISCUSSION}

These studies provide evidence that endogenous NE exerts a profound inhibitory effect on seizure induction. The enhanced susceptibility of $D b h-/-$ mice to such a diverse set of seizureinducing stimuli (convulsant stimuli potentially acting at excitatory or inhibitory receptors, sodium channels, and brainstem activation) (Olney et al., 1974; Schwob et al., 1980; Woodbury, 1980; Browning, 1985; Snead, 1992) suggests a "global" suppressive action of NE. The loss of NE's inhibitory action in $D b h-/-$ mice is also associated with increased c-fos mRNA expression after flurothyl-induced seizures. LC axons have a high degree of collateralization, and a single neuron can innervate several distant regions (Fallon and Loughlin, 1982; Loughlin et al., 1982). This diff use noradrenergic innervation pattern would allow NE release from LC terminals to suppress neuronal activity throughout the brain, including regions such as the cortex and hippocampus that are important in regulating seizures. Our studies support

\section{$D b h+/-\quad D b h-/-$}

Figure 3. Representative autoradiograms of c-fos mRNA expression after flurothyl-induced seizures. $A, C$, Flurothyl-induced c-fos mRNA expression in $D b h+/-$ mice without $(A)$ and with $(C)$ DOPS $(1$ $\mathrm{mg} / \mathrm{gm}) . B, D$, Flurothyl-induced c-fos mRNA expression in $D b h-/-$ mice without $(B)$ and with $(D)$ DOPS $(1 \mathrm{mg} / \mathrm{gm})$. Note the higher c-fos mRNA expression in $D b h-1-$ animals without DOPS $(B)$. DOPS $(1 \mathrm{mg} / \mathrm{gm})$ administration not only reduces c-fos mRNA expression of $D b h-/-$ mice (compare $B$ with $D$ ) but also normalizes c-fos mRNA expression in $D b h-/-$ mice relative to that in $D b h+/-$ mice (compare $C$ with $D$ ). Scale bar, $2 \mathrm{~mm}$. $N$, Neocortex.

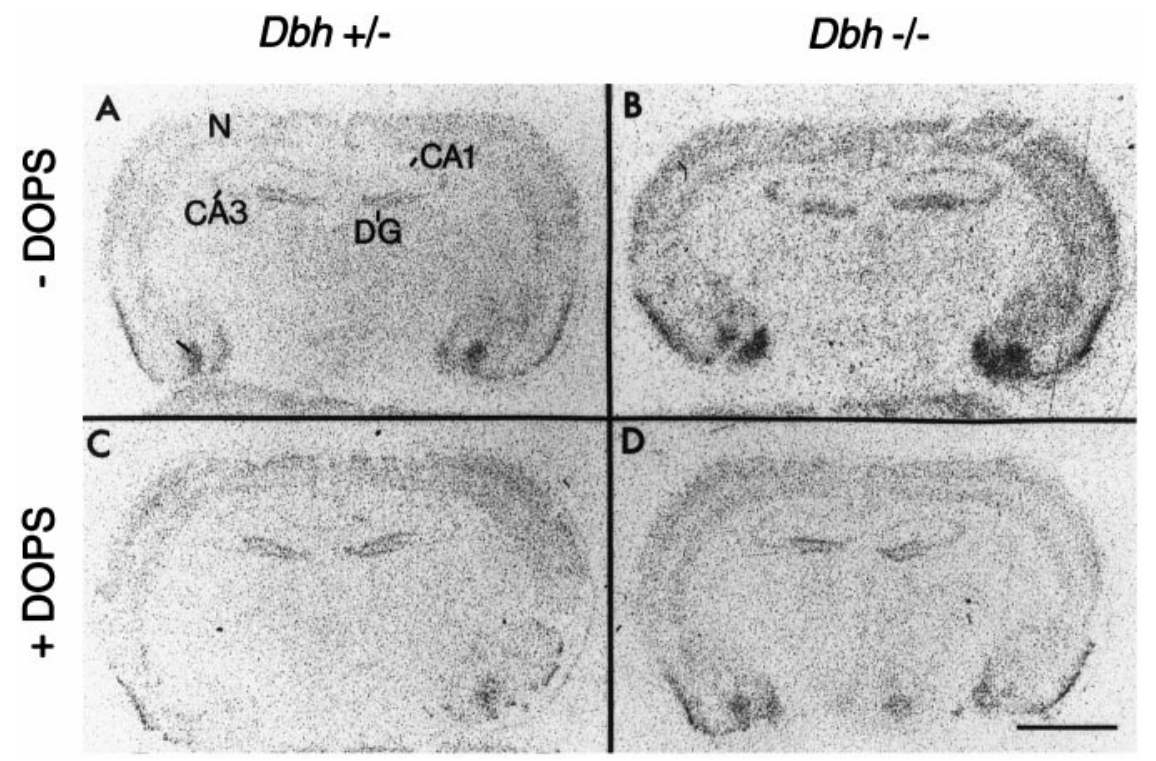



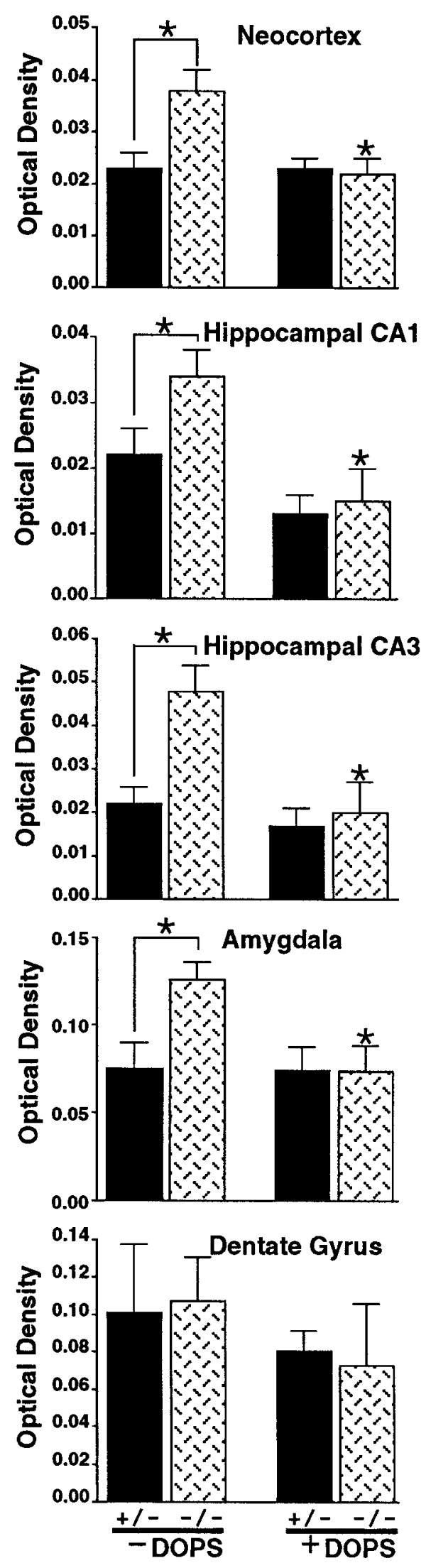

Figure 4. Quantification of flurothyl seizure-associated c-fos mRNA expression in the cortex, hippocampus (CA1, CA3, and DG), and amygdala in $D b h-/-$ and $D b h+/-$ mice, with and without DOPS $(1 \mathrm{mg} / \mathrm{gm})$. Flurothyl seizure-associated c-fos mRNA expression was significantly the hypothesis that there is an inverse relationship between the release of $\mathrm{NE}$ and seizure susceptibility; i.e., reducing $\mathrm{NE}$ release increases seizure susceptibility and increasing $\mathrm{NE}$ release has a protective effect against seizures.

Although many studies have implicated NE as an endogenous neuromodulator of seizure activity (Chen et al., 1954; Arnold et al., 1973; Libet et al., 1977; Jerlicz et al., 1978; Mason and Corcoran, 1979; Snead, 1987; Trottier et al., 1988; Turski et al., 1989; Sullivan and Osorio, 1991; Mishra et al., 1994), the evidence has not always been consistent. The data presented here demonstrate that a selective loss of NE from noradrenergic terminals is proconvulsant. One could argue that the NE deficiency in a knock-out mouse is not definitive because developmental changes associated with the deletion of the $D b h$ gene might contribute to the seizure-susceptibility phenotype seen in the $D b h-/-$ mice. However, we have also shown that increasing NE content in the CNS with DOPS administration (Thomas et al., 1998) can normalize seizure susceptibility of $D b h-/-$ mice. The ability of DOPS to rescue $D b h-/-$ mice has also been demonstrated with most other behavioral and physiological deficiencies in these mice (Thomas et al., 1995; Thomas and Palmiter, 1997a,b,c). DOPS rescue of noradrenergic function in the $D b h-/-$ mice suggests that there is a normal anatomical development of the "noradrenergic" system during gestation in these animals; this prediction of a normal pattern of noradrenergic terminals in $\mathrm{Dbh}-/-$ mice has been confirmed in studies of NE transporter-binding sites (D. Weinshenker, unpublished observation). If one assumes a normal organization of noradrenergic terminals in $D b h-/-$ mice, the conversion of DOPS to NE by L-aromatic amino acid decarboxylase could theoretically restore NE at appropriate terminals.

The absence of NE in $D b h-/-$ mice resulted in their greater sensitivity (i.e., enhanced seizure severity and higher mortality) to convulsant stimuli than that in $D b h+/-$ animals. After PTZand kainic acid-induced seizures, a higher percentage of the $D b h$ $-/-$ mice progressed to tonic extension and death. A similar finding was observed with flurothyl-induced seizures; although the percentage of animals progressing to tonic extension was the same for $D b h+/-$ and $D b h-/-$ mice without DOPS, more $D b h$ $-/-$ mice than $D b h+/-$ mice died after tonic extension. Administration of DOPS to both $D b h+/-$ and $D b h-/-$ mice had little effect on seizure severity but reduced the number of animals that died after tonic extension, especially in $D b h-/-$ mice. These results reflect the ability of DOPS to reverse the higher sensitivity of $D b h-/-$ mice to flurothyl-induced seizures. The increased survival of DOPS-treated Dbh $+/-$ mice may be caused by an elevation in NE content above a normal catecholamine content (Thomas et al., 1998).

Associated with the enhanced susceptibility to convulsant stimuli in $D b h-/-$ mice is an elevation in seizure-induced c-fos mRNA expression in the cortex, hippocampus (CA1 and CA3), and amygdala. The immediate early gene c-fos has long been

$\leftarrow$

higher in Dbh -/- mice without DOPS than in Dbh $+/-$ mice without DOPS in all regions but the dentate gyrus (mean \pm SEM; asterisks denote $p<0.01)$. DOPS $(1 \mathrm{mg} / \mathrm{gm})$ administration to $D b h-/-$ mice significantly reduced c-fos mRNA expression in all regions but the dentate gyrus (mean \pm SEM; asterisks denote $p<0.05$ ); c-fos mRNA expression in $D b h$ $-/-$ mice and $D b h+/-$ mice with DOPS was not significantly different. Basal c-fos mRNA expression in $D b h-/-$ mice is not significantly different from basal c-fos mRNA expression in $D b h+/-$ mice (data not shown). 
considered a marker of neuronal activity (Dragunow and Robertson, 1987; Morgan et al., 1987; Sonnenberg et al., 1989; Morgan and Curran, 1991). A correlation of seizure severity and c-fos expression has been observed with different convulsant stimuli (White and Price, 1993; Szot et al., 1997; Robbins et al., 1998). The enhanced seizure-induced c-fos mRNA expression in Dbh $-/-$ mice is not a function of an elevated basal c-fos state, because basal c-fos mRNA expression in $D b h-/-$ mice is not different from that in $D b h+/-$ mice. This enhanced c-fos mRNA expression in the CNS of $D b h-/-$ mice was measured in animals with a consistent behavioral seizure phenotype, suggesting a relationship between c-fos mRNA expression and seizure threshold. Acute DOPS administration normalized the seizureassociated c-fos mRNA expression in $D b h-/-$ mice. We conclude that the ability of the noradrenergic system to regulate seizure activity is a direct result of NE-mediated suppression of CNS excitability in such regions as the neocortex, hippocampus, and amygdala.

The ability of NE to have an inhibitory effect on seizures seems inconsistent with its general role on the arousal state of an animal. Noradrenergic neurons are active in awake animals but quiescent during sleep (Jouvet, 1969; Hobson et al., 1975; Aston-Jones and Bloom, 1981; Robbins, 1984). Basal c-fos mRNA expression in the cortex corresponds to the arousal state of the rat (Cirelli et al., 1996). When noradrenergic neurons in the LC were destroyed with 6-hydroxydopamine, the amount of basal c-fos mRNA expression in the cortex of the awake animal was reduced to levels comparable with that in an animal during sleep (Cirelli et al., 1996). Although these studies suggest a relationship between basal c-fos mRNA expression and NE, our study failed to find a change in basal c-fos mRNA expression in $D b h-/-$ mice relative to $D b h+/-$ mice. This difference emphasizes the gross effects of lesioning noradrenergic neurons, which results not only in the loss of NE but also affects the level of all neurotransmitters coreleased with NE. These cotransmitters released with NE may contribute to the basal excitability of the neurons.

The dual action of NE as an inhibitory and excitatory neurotransmitter can be attributed to the large diversity of noradrenergic receptors. Iontophoretic application of $\mathrm{NE}$ to neocortex or hippocampus results in both excitatory and inhibitory responses (Szabadi, 1979; Langmoen et al., 1981; Nishi et al., 1981; Segal, 1981; Madison and Nicoll, 1986; Waterhouse, 1986; Stanton, 1992). The excitatory response of NE appears to be mediated via the $\beta$-receptors and/or $\alpha 1$-ARs, whereas the inhibitory response is mediated via the $\alpha 2$-ARs (Curet and deMontigny, 1988; Parfitt et al., 1988; Licata et al., 1993). This dual action of NE on neuronal activity is apparent when synaptic NE content is elevated with NE reuptake blockers; these agents do not alter the animal's susceptibility to convulsant stimuli (Kleinrok et al., 1991; Yacobi and Burnham, 1991). We postulate that the anticonvulsant action of $\mathrm{NE}$ is mediated via $\alpha 2$-ARs. Indeed, agonists selective for the $\alpha 2$-ARs have been shown to exert anticonvulsant effects against audiogenic seizures in mice, as well as against PTZ-, kainic acid-, and bicuculline-induced seizures; $\alpha 2-\mathrm{AR}$ antagonists have the reverse effect (Papanicolaou et al., 1982; Baran et al., 1985; Loscher and Czuczwar, 1987; Fletcher and Forster, 1988; Jackson et al., 1991). However, it has not been determined whether the anticonvulsant effect of $\alpha 2$-AR agonists is mediated via the pre- or postsynaptic receptors. A recently developed transgenic mouse with nonf unctional $\alpha 2 \mathrm{~A}$-ARs (MacMillan et al.,
1996) responded to a kindling paradigm (a process of repetitively applied stimuli resulting in generalized seizures) similarly to wild-type mice treated with an $\alpha 2$-AR antagonist (Janumpalli et al., 1998). Although the $D b h-/-$ mice are not the same as the $\alpha 2 \mathrm{~A}-\mathrm{AR}$ mutant, the combined results provide compelling evidence that NE acting at least partially via inhibitory postsynaptic $\alpha 2$-ARs dampens seizure excitability. The lack of spontaneous seizure activity in $D b h-/-$ mice suggests that NE release may only become important under conditions of high activity (e.g., seizures) when the LC is sufficiently activated; i.e., NE serves as a potent modulator of excitability.

In conclusion, the data presented here show unambiguously that $\mathrm{NE}$ is capable of modulating seizure activity induced by different convulsant stimuli. The pervasive inhibitory action of $\mathrm{NE}$ on excitability is reflected in the increased seizure-associated c-fos mRNA expression in the $D b h-/-$ mice. Because galanin and NPY are also inhibitory neuromodulators that are coreleased from the same terminals as NE, it seems that the noradrenergic projection system may use multiple neurotransmitters to dampen excitability. Because of this complexity, the $D b h-/-$ mice provide an especially useful and new system to examine the pathways through which NE regulates seizure activity.

\section{REFERENCES}

Arnold PS, Racine RJ, Wise RS (1973) Effects of atropine, reserpine, 6-hydroxydopamine and handling on seizure development in the rat. Exp Neurol 40:457-470.

Aston-Jones G, Bloom FE (1981) Activity of norepinephrine-containing locus coeruleus neurons in behaving rats anticipates fluctuations in the sleep-waking cycle. J Neurosci 1:876-886.

Baraban SC, Hollopeter G, Erickson JC, Schwartzkroin PA, Palmiter RD (1997) Knock-out mice reveal a critical antiepileptic role for neuropeptide Y. J Neurosci 17:8927-8936.

Baran H, Sperk G, Hortnagl H, Sapetschnig G, Hornykiewicz O (1985) Alpha 2-adrenoceptors modulate kainic acid-induced limbic seizures. Eur J Pharmacol 113:263-269.

Browning RA (1985) Role of the brain-stem reticular formation in tonicclonic seizures: lesions and pharmacological studies. Fed Proc 44:2425-2431.

Browning RA, Wade DR, Marcinczyk M, Long GL, Jobe PC (1989) Regional brain abnormalities in norepinephrine uptake and dopamine $\beta$-hydroxylase activity in the genetically epilepsy-prone rat. J Pharmacol Exp Ther 249:229-235.

Chen G, Ensor GR, Bohner B (1954) A facilitation action of reserpine on the central nervous system. Proc Soc Exp Biol Med 86:507-510.

Cirelli C, Pompeiano M, Tononi G (1996) Neuronal gene expression in the waking state: a role for the locus coeruleus. Science 274:1211-1215.

Curet O, deMontigny C (1988) Electrophysiological characterization of adrenoceptors in the rat dorsal hippocampus. I. Receptors mediating the effect of microiontophoretically applied norepinephrine. Brain Res 475:35-46.

Curran T, Gordon MB, Rubino KL, Sambucetti LC (1987) Isolation and characterization of the c-fos (rat) cDNA and analysis of posttranslational modifications in vitro. Oncogene 2:79-84.

Dailey JW, Jobe PC (1986) Indices of noradrenergic function in the central nervous system of seizure-naive genetically epilepsy-prone rats. Epilepsia 27:665-670.

Dailey JW, Mishra PK, Ko KH, Penny JE, Jobe PC (1991) Noradrenergic abnormalities in the central nervous system of seizure-naive genetically epilepsy-prone rats. Epilepsia 32:168-173.

Dailey JW, Mishra PK, Ko KH, Penny JE, Jobe PC (1992) Serotonergic abnormalities in the central nervous system of seizure-naive genetically epilepsy-prone rats. Life Sci 50:319-326.

Dichter MA (1994) Emerging insights into mechanisms of epilepsy: implications for new antiepileptic drug development. Epilepsia 35[Suppl 4]:s51-s57. 
Dragunow M, Robertson HA (1987) Kindling stimulation induces c-fos protein(s) in granule cells of the rat dentate gyrus. Nature 329:441-442.

Erickson JC, Clegg KE, Palmiter RD (1996) Sensitivity to leptin and susceptibility to seizures of mice lacking neuropeptide Y. Nature 381:415-421.

Faingold CL, Gehlach B, Caspary DM (1986) Decreased effectiveness of GABA-mediated inhibition in the inferior colliculus of the genetically epilepsy-prone rat. Exp Neurol 93:145-159.

Fallon JH, Loughlin SE (1982) Monoamine innervation of the forebrain: collateralization. Brain Res Bull 9:295-307.

Fletcher A, Forster EA (1988) A proconvulsant action of selective $\alpha 2$ adrenoceptor antagonists. Eur J Pharmacol 151:27-34.

Franklin KBJ, Paxinos G (1997) The mouse brain in stereotaxic coordinates. New York: Academic.

Hara M, Sasa M, Kawabata A, Serikawa T, Yamada T, Yamada J, Takaori S (1993) Decreased dopamine and increased norepinephrine levels in the spontaneously epileptic rat, a double mutant rat. Epilepsia 34:433-440.

Hobson JA, McCarley RW, Wyzinski PW (1975) Sleep cycle oscillation: reciprocal discharge by two brainstem neuronal groups. Science 189:55-58.

Jackson HC, Dickinson SL, Nutt DJ (1991) Exploring the pharmacology of the pro-convulsant effects of alpha 2-adrenoceptor antagonists in mice. Psychopharmacology (Berl) 105:558-562.

Janumpalli S, Butler LS, MacMillan LB, Limbird LE, McNamara JO (1998) A point mutation (D79N) of the alpha2a-adrenergic receptor abolishes the antiepileptic action of endogenous norepinephrine. J Neurosci 18:2004-2008.

Jerlicz M, Kostowski W, Bidzi’nski A, Hauptman M, Dymecki J (1978) Audiogenic seizures in rats: relation to noradrenergic neurons of the locus coeruleus. Acta Physiol Pol 29:409-412.

Jobe PC, Ko KH, Dailey JW (1984) Abnormalities in norepinephrine turnover rate in the central nervous system of the genetically epilepsyprone rat. Brain Res 290:357-360.

Jouvet M (1969) Biogenic amines and the states of sleep. Science 163:32-41.

King GA, Burnham WM (1982) Alpha 2-adrenergic antagonists suppress epileptiform EEG activity in a petit mal seizure model. Life Sci 30:293-298.

Kleinrok Z, Gustaw J, Czuczwar SJ (1991) Influence of antidepressant drugs on seizure susceptibility and the anticonvulsant activity of valproate in mice. J Neural Transm [Suppl] 34:85-90.

Langmoen IA, Segal M, Andersen P (1981) Mechanisms of norepinephrine actions on hippocampal pyramidal cells in vitro. Brain Res 208:349-362.

Lapin IP, Ryzor IV (1990) Effect of catecholaminergic drugs on quinolinate- and kynurenine-induced seizures in mice. J Neurol Transm Gen Sect 82:55-65.

Lauterborn JC, Ribak CR (1989) Differences in dopamine betahydroxylase immunoreactivity between the brains of genetically epilepsy-prone and Sprague-Dawley rats. Epilepsy Res 4:161-176.

L'Heureux R, Dennis T, Curet O, Scatton B (1986) Measurement of endogenous noradrenaline release in the rat cerebral cortex in vivo by transcortical dialysis: effects of drugs affecting noradrenergic transmission. J Neurochem 46:1794-1801.

Libet B, Gleason CA, Wright EW, Feinstein B (1977) Suppression of an epileptiform type of electrocortical activity in the rat by stimulation of the locus coeruleus. Epilepsia 18:451-462.

Licata F, Li-Volsi G, Maugeri G, Ciranna L, Santangelo F (1993) Effects of noradrenaline on the firing rate of vestibular neurons. Neuroscience 53:149-158.

Loscher W, Czuczwar SJ (1987) Comparison of drugs with different selectivity for central alpha1- and alpha2-adrenoceptors in animal models of epilepsy. Epilepsy Res 1:165-172.

Loughlin SE, Foote SL, Fallon JH (1982) Locus coeruleus projections to cortex: topography, morphology and collateralizations. Brain Res Bull 9:287-294

MacMillan LB, Hein L, Smith MS, Piascik MT, Limbird LE (1996) Central hypotensive effects of the $\alpha 2 \mathrm{a}$-adrenergic receptor subtype. Science 273:801-803.

Madison DV, Nicoll RA (1986) Actions of noradrenaline recorded in- tracellularly in rat hippocampal CA1 pyramidal neurons in vitro. J Physiol (Lond) 372:221-244.

Mason ST, Corcoran ME (1979) Catecholamines and convulsions. Brain Res 170:497-507.

Mazarati AM, Hal'aszi E, Telegdy G (1992) Anticonvulsive effects of galanin administered into the central nervous system upon the picrotoxin-kindled seizure syndrome in rats. Brain Res 589:164-166.

Mazarati AM, Liu H, Soomets U, Sankar R, Shin D, Katsumori H, Langel U, Wasterlain CG (1998) Galanin modulation of seizures and seizure modulation of hippocampal galanin in animal models of status epilepticus. J Neurosci 18:10070-10077.

Meyerhoff JL, Carter RE, Yourick DL, Slusher BS, Coyle JT (1992) Genetically epilepsy-prone rats have increased brain regional activity of an enzyme which liberates glutamate from $N$-acetyl-aspartyl-glutamate. Brain Res 593:140-143.

Mishra PK, Burger RL, Bettendorf AF, Browning RA, Jobe PC (1994) Role of norepinephrine in forebrain and brainstem seizures: chemical lesioning of locus ceruleus with DSP4. Exp Neurol 125:58-64.

Morgan JI, Curran T (1991) Proto-oncogene transcription factors and epilepsy. Trends Pharmacol Sci 12:343-349.

Morgan JI, Cohen DR, Hempstead JL, Curran T (1987) Mapping patterns of c-fos expression in the central nervous system after seizure. Science 237:192-197.

Murray TF, Sylvester D, Schultz CS, Szot P (1985) Purinergic modulation of pentylenetetrazol seizure threshold in the rat. Neuropharmacology 24:761-766.

Nishi H, Watanabe S, Ueki S (1981) Effects of monoamines injected into the hippocampus on hippocampal seizure discharges in the rabbit. J Pharmacobiodyn 4:7-14.

Noebels JL (1986) Mutational analysis of inherited epilepsies. Adv Neurol 44:97-113.

Olney JW, Rhee V, Ho OL (1974) Kainic acid: a powerful neurotoxic analogue of glutamate. Brain Res 77:507-512.

Papanicolaou J, Summers RJ, Vajda FJE, Louis WJ (1982) The relationship between alpha 2-adrenoceptor selectivity and anticonvulsant effect in a series of clonidine-like drugs. Brain Res 241:393-397.

Parfitt KD, Freedman R, Bickford-Wimer PC (1988) Electrophysiological effects of locally applied noradrenergic agents at cerebellar Purkinje neurons: receptor specificity. Brain Res 462:242-251.

Prichard JW, Gallagher BB, Glaser GH (1969) Experimental seizurethreshold testing with flurothyl. J Pharmacol Exp Ther 166:170-178.

Robbins CA, Kim DW, Szot P, Rho JM, White SS, Schwartzkroin PA (1998) c-Fos mRNA expression is increased in mouse brain after seizure induced by flurothyl. Epilepsia 39[Suppl 6]:26.

Robbins TW (1984) Cortical noradrenaline, attention and arousal. Psychol Med 14:13-21.

Schwob JE, Fuller T, Price JL, Olney JW (1980) Widespread patterns of neuronal damage following systemic or intracerebral injections of kainic acid: a histological study. Neuroscience 5:991-1014.

Segal M (1981) The action of norepinephrine in the rat hippocampus: intracellular studies in the slice preparation. Brain Res 206:107-128.

Snead III OC (1987) Noradrenergic mechanisms in gammahydroxybutyrate-induced seizure activity. Eur J Pharmacol 136:103-108.

Snead III OC (1992) Pharmacological models of generalized absence seizures in rodents. J Neural Transm Suppl 35:7-19.

Sonnenberg JL, Mitchelmore C, McGregor-Leon PF, Hempstead J, Morgan JI, Curran T (1989) Glutamate receptor agonists increase the expression of Fos, Fra and AP-1 DNA binding activity in the mammalian brain. J Neurosci Res 24:72-80.

Stanton PK (1992) Noradrenergic modulation of epileptiform bursting and synaptic plasticity in the dentate gyrus. Epilepsy Res Suppl 7:135-150.

Sullivan HC, Osorio I (1991) Aggravation of penicillin-induced epilepsy in rats with locus ceruleus lesion. Epilepsia 32:591-596.

Szabadi E (1979) Adrenoceptors on central neurons: microelectrophoretic studies. Neuropharmacology 18:831-843.

Szot P, White SS, Veith RC (1997) Effect of pentylenetetrazol on the expression of tyrosine hydroxylase mRNA and norepinephrine and dopamine transporter mRNA. Mol Brain Res 44:46-54.

Tacke U, Kolonen S (1984) The effect of clonidine and yohimbine on audiogenic seizures (AGS) in rats. Pharmacol Res Commun 16:1019-1030. 
Thomas SA, Palmiter RD (1997a) Disruption of the dopamine $\beta$-hydroxylase gene in mice suggests roles for norepinephrine in motor function, learning, and memory. Behav Neurosci 111:579-589.

Thomas SA, Palmiter RD (1997b) Thermoregulatory and metabolic phenotypes of mice lacking noradrenaline. Nature 387:94-97.

Thomas SA, Palmiter RD (1997c) Impaired maternal behavior in mice lacking norepinephrine and epinephrine. Cell 91:583-592.

Thomas SA, Matsumoto AM, Palmiter RD (1995) Noradrenaline is essential for mouse fetal development. Nature 374:643-646.

Thomas SA, Marck BT, Palmiter RD, Matsumoto AM (1998) Restoration of norepinephrine and reversal of phenotypes in mice lacking dopamine $\beta$-hydroxylase. J Neurochem 70:2468-2476.

Trottier S, Lindvall O, Chauvel P, Bjorklund A (1988) Facilitation of focal cobalt-induced epilepsy after lesions of the noradrenergic locus coeruleus system. Brain Res 454:308-314.
Turski L, Ikonomidou C, Turski WA, Bortolotto ZA, Cavalheiro ES (1989) Review: cholinergic mechanisms and epileptogenesis. The seizures induced by pilocarpine: a novel experimental model of intractable epilepsy. Synapse 3:154-171.

Waterhouse BD (1986) Electrophysiological assessment of monoamine synaptic function in neuronal circuits of seizure susceptible brains. Life Sci 39:807-818.

White LE, Price JL (1993) The functional anatomy of limbic status epilepticus in the rat. 1. Patterns of $\left[{ }^{14} \mathrm{C}\right] 2$-deoxyglucose uptake and Fos immunocytochemistry. J Neurosci 13:4787-4809.

Woodbury DM (1980) Convulsant drugs: mechanism of action. Adv Neurol 27:249-303.

Yacobi R, Burnham WM (1991) The effect of tricyclic antidepressants on cortex- and amygdala-kindled seizures in the rat. Can J Neurol Sci 18:132-136. 